\title{
Predictors for Nurses and Midwives' Readiness towards Self-Directed Learning: An Integrated Review
}

${ }^{1}$ Karpagam Chakkaravarthy, ${ }^{2}$ Norzihan Ibrahim ${ }^{3}$ Mardiah Mahmud, ${ }^{4}$ Munikumar Ramasamy Venkatasalu

Running Head: Predictors for Nurses and Midwives' Readiness towards Self-Directed Learning

Total Word count (excluding reference): 4167

\section{${ }^{1}$ Karpagam Chakkaravarthy}

Phd Candidate in Nursing

PAP Rashidah Sa'adatul Bolkiah Institute of Health Sciences

Universiti Brunei Darussalam

Jalan Tungku Link Gadong, BE1410

Negara Brunei Darussalam

karpaga78@yahoo.co.in

\section{${ }^{2}$ Norzihan Ibrahim}

Nursing Officer Special Grade

Department of Nursing Services

Ministry of Health

Brunei Darussalam

Negara Brunei Darussalam

norzihan.ibrahim@MOH.GOV.BN

\section{${ }^{3}$ Dr Mardiah Binti Hj Mahmud}

Lecturer in Nursing

PAP Rashidah Sa'adatul Bolkiah Institute of Health Sciences

Universiti Brunei Darussalam

Jalan Tungku Link Gadong, BE1410

Negara Brunei Darussalam

mardiah.mahmud@ubd.edu.bn

\section{Dr Munikumar RAMASAMY VENKATASALU}

Professor in Cancer and Palliative care

PAP Rashidah Sa'adatul Bolkiah Institute of Health Sciences

Universiti Brunei Darussalam

Jalan Tungku Link Gadong, BE1410

Negara Brunei Darussalam

Tel: +6732463001 Ext: 2213

kumar.venkatasalu@ubd.edu.bn 


\section{Conflict of interest statement:}

Author declares no conflict of interest.

\section{Funding statement:}

This project was not received any funding support. 
Predictors for Nurses and Midwives' Readiness towards Self-Directed Learning

\title{
Predictors for Nurses and Midwives' Readiness towards Self-Directed Learning: An Integrated Review
}

\begin{abstract}
Aim

To systematically review the existing evidence on predictors for nurses and midwives' readiness towards Self-directed Learning (SDL).

\section{Background}

Increased complexities in healthcare settings demand that nurses and midwives become involved in lifelong learning by means of self-directed learning (SDL) for delivering quality healthcare. More evidence is available for the self-directed learning readiness (SDLR) of nursing and midwifery students, less is systematically derived on predictors for nurses and midwives' readiness to SDL.
\end{abstract}

\section{Design}

An integrative systematic review.

\section{Methods}

Systematic searches were carried out using the following five electronic databases: PubMed, Science Direct, Google Scholar, Ovid Medline and Embase. Studies published in English language from 2000-2017 were included. The integrative systematic review framework developed by Whittemore and Knafl (2005) was used to analyse and summarise the key themes.

\section{Results}

Of 804 initial screening papers, in total of eight eligible studies (six quantitative and two qualitative) were found. Integrative analysis resulted in four themes as predictors for nurses and midwives' readiness towards SDL: 1) personal characteristics, 2) working environment, 3) online learning and SDLR, and 4) process of SDL. Review found that, although demographic characteristics of nurses and midwives does not influence their SDLR, work environment often influences their SDLR. Furthermore, nurses and midwives have a positive interest in online learning that is often used to improve their knowledge acquisition.

\section{Conclusion}

The review concludes that qualified nurses and midwives have a unique SDL predictors and process; hence, a personalized SDL programme should be prescribed based on personality traits so as to achieve better SDL outcomes. Future research should address the facilitating factors for SDLR, barriers to SDLR and strategies to improve SDLR among nurses and more importantly midwives, as limited evidence is available with respect to the latter.

Key words: Nurses, Midwives, Self-directed Learning, Lifelong learning, Readiness, Integrative review. 


\section{Introduction}

Increased complexities in global health care settings require nurses and midwives to keep abreast of challenges in providing safe and quality care (Chambers et al., 2013). On the other hand, with the prevailing global cost-saving efforts of healthcare financing trends, increased demands on the healthcare workforce often challenge the provision of continuing protected and sponsored professional learning time for nurses and midwives (Purkis and Gabb, 2013). Furthermore, nurses and midwives need to fulfil the demands of professional regulators such as the Nursing Board for Brunei and the Nursing and Midwifery Council UK to engage in revalidation requirements of continued professional learning (Middleton and Llewellyn, 2016). For example, the Nursing Board for Brunei (NBB) which is the nursing and regulatory body for Brunei Darussalam states in its standards of practice for registered nurses and midwives (Standard 8) that they should enhance their professional competence by participating in lifelong learning developing their own knowledge, skills and attitudes, either formally or informally through SDL. Alternatively, the current open science era makes available diverse educational sources such as online learning, which are either free or cost effective ways of educating nurses and midwives to update their professional knowledge and practice (Dalhem and Saleh, 2014). In addition, several studies identified that the prerequisite for successful adaptation to a complex healthcare system is to become involved in lifelong learning through a self-directed learning approach (Sharples and Moseley, 2010, O'shea, 2003, Salmond and Echevarria, 2017, Hosseini \& Assareh, 2011).

Self-directed learning (SDL) is undertaking individual responsibility to identify learning needs, devise individual learning objectives and seek learning resources in order to engage in selflearning activities and continuously self-evaluate learning (Knowles, 1975, Knowles et al., 2014). Studies report that SDL based lifelong learning approaches foster nurses and midwives to develop many competencies (Bahn, 2007; Cleary and Freeman, 2006). Studies among medical students (Murad and Varkey, 2008) and nursing students (Yang and Jiang, 2014) reported that SDL is an effective method of lifelong learning to develop and promote confidence in clinical practice, which relies on the readiness of the individual towards SDL. Readiness towards SDL is a key and integral part of SDL and is closely related to the positive attitude of nurses (Farokhi 
Far et al., 2002). Self-directed learning readiness (SDLR) is defined as the level of personal attitude, learning ability and intention for knowledge acquisition needed for self-directed learning (Wiley, 1983). A study among nursing students by Şenyuva and Kaya (2014) reported that web based self-directed learning resulted in high scores for SDLR. Another study among nursing students by El et al. (2014) reported that students with a high degree of self-control was a key indicator for SDLR. Similarly, a study among medical students by Soliman and Al-Shaikh (2015) reported that participants who scored highly for 'desire for learning' was an indicator and key domain for SDL.

Existing reviews of SDL and SDLR were majorly focused on nursing and midwifery students (Murad and Varkey, 2008, Collins, 2004, Klunklin et al., 2010). To date, no reviews have been published about nurses and midwives' readiness towards SDL. This integrative review aimed to systematically review the existing evidence on predictors for nurses and midwives' readiness towards SDL. The synthesised knowledge from the evidence can guide nurses and midwives effectively and therefore promote and enhance their readiness towards SDL. Such knowledge can also guide nursing policymakers in developing strategies to promote SDL.

\section{Methods}

\section{Study Design}

An integrated review method of Whittemore and Knafl (2005) was adopted for this literature review. Integrated reviews are commonly used to analyse the purpose of any review, critique existing knowledge that allow 'reconceptualization of the expanding and more diversified knowledge base' of the selected topic (Torraco, 2005). The reasons for choosing an integrative review for the purposes of this study were as follows:

(a) Limited research and development, particularly with respect to SDLR among nurses and midwives,

(b) The majority of publications that focus on SDLR relate to nursing education and student nurses,

(c) The efficiency of the integrative review method in combining different methodologies. 


\section{Search process and search strategy}

An extensive search of the literature from 2000 to January 2017 was performed using five databases: MEDLINE, PubMed, ScienceDirect, Embase and Google Scholar. Two reviewers (KC and MRV) and a Library Information specialist constructed a search strategy that comprised of analysing the key text words and index terms of relevant literature. Search terms used included nurse* OR nurse manager* OR nurse educator* OR nurse leader* AND midwife* OR midwifery AND self-directed learning OR self-directed learning OR non formal learning OR non-formal learning OR life-long learning OR lifelong learning OR work place learning OR work-place learning AND readiness OR commitment*. Data retrieval was performed from June 2017 through till November 2017. The search strategy was carried out based on the guided principles of the respective databases and stated inclusion and exclusion criteria were followed rigorously (see Table 1).

\section{[Insert Table 1 Here]}

\section{Search Outcomes}

Three reviewers were involved in identifying and selecting the relevant studies through different stages by following the guidelines of Preferred Reporting Items for Systematic Reviews and Meta-Analysis (PRISMA) (Moher et al., 2009) (See Fig 1). At the initial stage, the search identified 804 studies based on abstract and title information. The studies were examined systematically and individually to determine whether the identified studies met the inclusion criteria. Following this, removal of duplicates resulted in identifying 53 relevant studies. All 53 papers were examined in full against inclusion and exclusion criteria that resulted in the final inclusion of 11 papers. Of these 11, three studies were further excluded as these concerned selfdirected learning related to allied health professionals (AHP). One of the latter studies included a mixed sample of AHP and nurses, therefore reviewers agreed to exclude this as it contained mixed data. All reviewers were involved in the final stage of assessing the relevancy and accuracy of the included studies of the literature search. Eight $(n=8)$ studies that fully met the 
inclusion criteria were deemed as eligible studies by all of the reviewers through the process of thorough reading and a consensus was reached in a face-to-face meeting. Papers that did not meet the inclusion criteria were excluded.

\section{[Insert Figure 1 Here]}

\section{Quality Assessment and Data Abstraction}

In systematic reviews, primary sources of identified studies are evaluated for the purpose of assigning quality scores. However, the aim of an integrated review is to combine methodologies in order develop an expanded knowledge base, rather than assigning quality scores. Hence, a quality scoring exercise was not performed (Whittemore and Knafl, 2005). On the other hand, two standardised data extraction tools (JBI QARI data extraction tool for experimental/observational studies and JBI QARI data extraction tool for interpretive and critical care research) for empirical studies were used to analyse the overall quality by assessing the methodological features systematically (Peters et al., 2015). This helped to assess each study for its congruity between methodology and data collection, and data analysis with respect to the study aims. A third reviewer (SE) was involved to resolve any potential disputes arising between the two reviewers ( $\mathrm{KC}$ and $\mathrm{MRV}$ ) when assessing methodological quality. All relevant data that explored the nurses and midwives' readiness towards SDL from the primary studies was extracted. Finally, the synthesised information from all eight studies was tabulated under five headings: author and year; aim and objectives; sample; sampling technique and settings, methodology and results (see Table 2).

\section{[Insert Table 2 Here]}

\section{Data Synthesis}

The framework of the analysis followed the Whittemore and Knafl (2005) principles of integrative review inclusive of the following stages: data reduction, data display, data comparison and conclusion drawing and verification. 


\section{Data Reduction}

Data reduction techniques utilise the process of coding the data in order to 'simplify, abstract, focus and organise it into manageable features' (Ramasamy Venkatasalu et al., 2017). The study adopted subgrouping and single page tabulation as valid and reliable coding techniques in order to enhance methodological rigour (Broome, 2000, Brown et al., 2003). At the subgrouping stage, all included studies $(n=8)$ were arranged based on their research methodology, nature of sample (nurses, nurse educator and nurse leaders, preceptors and head nurse) followed by the 'predetermined conceptual classification' (Whittemore and Knafl, 2005) or primary objective of this review (SDLR) and later evaluated by topic. At the single page tabulation stage, the data of each study was reduced to a single page, which facilitated the systematic comparison of the aforementioned variables. Moreover, this aided assembling of the data into a manageable feature.

\section{Data Display}

The extracted single page data of eight eligible studies was gathered and displayed in tabulated form (see Table 2). Displayed data improves the 'visualization of patterns and relationships' between and within eligible studies for ease of interpretation (Whittemore and Knafl, 2005).

\section{Data Comparison}

The displayed data in Table 2 was examined, compared and analysed cautiously and rigorously by the two reviewers ( $\mathrm{KC}$ and $\mathrm{MRV}$ ). Using this data comparison method enhanced the process of identifying themes that had similar 'patterns and relations' (Whittemore and Knafl, 2005).

\section{Drawing and Verification}

The reviewers interpreted the patterns and relationships in the compared data to formulate themes. Potential disputes between the two reviewers ( $\mathrm{KC}$ and $\mathrm{MRV}$ ) were resolved through discussion and agreement with the other two reviewers (MA and SE). Decisions were arrived at through discussion and careful analysis before the final themes were determined. 


\section{Results}

This integrative review reports the evidence on predictors for nurses and midwives' readiness towards SDL. Eight studies met the inclusion criteria: six quantitative (Malekian et al.,2014; Chen et al., 2012;Gagnon et al., 2015; Ito et al., 2016; Takase et al., 2015; Mayer, Andrusyszyn \& Iwasiw, 2005) and two qualitative studies (Ghiyasvandian et al., 2016; Nokdee, 2007) The focus of the eligible studies was on the following four themes:

1) Personal characteristics (Malekian et al., 2014; Ito et al., 2016; Mayer, Andrusyszyn, \& Iwasiw, 2005).

2) Work environment (Takase et al., 2015; Nokdee, 2007; Ito et al., 2016; Ghiyasvandian et al., 2016).

3) Online learning and SDLR (Gagnon et al., 2015; Nokdee, 2007).

4) The process of SDL (Ghiyasvandian et al., 2016; Chen et al., 2012; Nokdee, 2007).

Overall, the age distribution of participants in all studies ranged from 20 to 50 years (Malekian et al.,2014; Nokdee,2007; Gagnon et al., 2015; Ito et al., 2016; Takase et al., 2015; Chen et al., 2012; Mayer, Andrusyszyn, \& Iwasiw, 2005). The working experience of participants ranged from 1 to 30 years (Malekian et al., 2014; Takase et al., 2015; Nokdee et al., 2007; Ya-Lin Chen et al., 2012; Mayer, Andrusyszyn \& Iwasiw, 2005). The majority of participants (80\%) were female. All eight studies involved nurses and one of the studies included midwives as well as nurses. From the various studies, the following facts were ascertained: $73 \%$ of participants (Malekian et al.,2014) and 46\% of participants (Chen et al., 2012) were married; 91.6\%, 39\%, $31.5 \%$ and $66 \%$ of participants had a bachelor degree qualification (Malekian et al.,2014; Takase et al., 2015; Ito et al., 2016; Gagnon et al., 2015) and the highest qualification for participants was a Masters degree; professional roles ranged from staff nurse to head nurse and included Nurse Educators (Malekian et al.,2014; Nokdee,2007; Gagnon et al., 2015; Ito et al., 2016; Takase et al., 2015; Chen et al., 2012; Mayer, Andrusyszyn, \& Iwasiw, 2005). The participants were either employed in general wards or critical care units. The studies were conducted in the following countries: Japan; Thailand; Taiwan; Iran and Canada (Ito et al., 2016; Nokdee,2007; Chen et al., 2012; Malekian et al.,2014; Gagnon et al., 2015; Takase et al., 2015; Mayer, Andrusyszyn, \& Iwasiw, 2005). 
Descriptive integrated thematic analysis resulted in four themes as predictors for nurses and midwives' readiness towards SDL: personal characteristics, work environment, online learning and SDLR and the process of SDL.

\section{Theme 1: Personal characteristics}

Four studies in this review reported on the relationship between nurses' personal characteristics such as attitude, ability and personality and their SDLR (Malekian et al., 2014; Ito et al., 2016; Mayer, Andrusyszyn, \& Iwasiw, 2005; Nokdee, 2007). The study of 314 Iranian nurses by Malekian et al. (2014) reported that the age, gender and marital status of the nurses did not influence their key domains of SDLR, which were willingness to learn, self-regulation and selfmanagement. However, the study did find that work experience and past academic achievement of nurses had a significant correlation with the self-management of the nurses' SDLR. Similarly, the study of 73 nurses working in a Neuro ward by Mayer, Andrusyszyn, \& Iwasiw (2005) reported that age, gender, education, years in nursing practice and additional responsibilities did not influence the self-efficacy towards SDL. The study did however find a correlation between the positive attitude of nurses and self-efficacy towards SDL. Furthermore, the study of 1655 Japanese nurses by Ito et al. (2016) reported that their SDLR was associated with the nurses' intention to grow and develop accountability in self-learning. A study utilising qualitative interviews and participant observation of nurses and nurse educators in Thailand found that selfregulation, individual accountability, learning ability and problem solving skills were four essential personal characteristics for nurses as self-directed learners (Nokdee, 2007).

\section{Theme: 2 Work Environment}

Three of seven eligible reviewed studies reported that the work environment often influences SDLR (Nokdee, 2007; Ghiyasvandian et al., 2016; Malekian et al., 2014). Nokdee (2007) reported that a friendly clinical team in the working environment comprising peer healthcare professionals, patient and carers and family members of nurses has a significant impact on the nurses' SDL. Interview data from 19 Iranian nurses in Ghiyasvandian et al. (2016) suggested that working environment activities such as observation in the clinical environment, interviewing the 
patient, listening and being involved in routine clinical rounds with the health care professionals influences nurses' SDLR. Findings from the study by Malekian et al. (2014) also found a significant relationship between SDLR and clinical work experience. Similarly, the study by Takase et al. (2015) among 954 Japanese nurses and midwives reported that self-reported competence increased in association with the learning from feedback and experience.

\section{Theme 3: Online learning and SDLR}

Two eligible studies reported the role of online learning in nurses' SDLR. A pre-test and post test study by Gagnon et al. (2015) assessed the level of knowledge acquisition and self-directed readiness of 36 Canadian nurses and 47 Spanish nurses before and after their online learning exercise in the subject of evidence based practice. Results found that nurses had increased levels of SDLR domains, which were associated with online learning. Indeed, a qualitative study by Nokdee (2007) also reported that nurses showed greater interest and often used online learning as SDL sources for searching (and researching) interesting topics related to patient management.

\section{Theme 4: The process of SDL}

Three studies in this review reported about the process of SDL activities as a means of skill development among nurses and midwives (Nokdee, 2007; Ghiyasvandian et al., 2016; Chen et al., 2012). Nokdee (2007) reported that nurses adopt diverse 'intellectual and experiential activities' such as learning based on their own interest, learning from observation and learning from experience, which allows them to improve their personal performance and acquire clinical expertise. Furthermore, Ghiyasvandian et al. (2016) reported that the self-learning activities of nurses encompassed knowledge acquisition through individual awareness, self-analysis, logical reasoning and skill development as well as engaging in training activities and individual management. In addition, a cross-sectional survey by Chen et al. (2012) using a convenience sample of 243 nurses from Taiwan reported that the internal locus of control characteristics such as desired goal, self-control and self-management, which are similar to the key domains of SDLR were the significant predictors of teaching competencies among the nurse preceptors. 


\section{Discussion}

Existing literature evidence focused mainly on student nurses and midwives' readiness towards SDL (Wang \& Liu, 2008; Collins, 2004; Klunklin et al., 2010; Van Rensburg et al., 2015). The aim of this study review was to synthesise the existing evidence of nurses and midwives' readiness towards SDL. It is clear however that the limitations of this study comprised a limited number of studies and an unequal balance of nurses and midwives in the reviewed studies (seven studies relate to nurses only and one to nurses and midwives), which influence the scope of the review findings.

Firstly, the review found that demographic characteristics of nurses such as age, gender, marital status, educational qualification, working experience and additional administrative responsibilities does not influence the nurses and midwives' SDLR. However, nurses' personality traits such as feeling of independence, willingness to learn, individual learning accountability, and self-efficacy in learning analysis were demonstrated to be influencers of SDL. Similar findings on the positive relationship between SDLR and personality traits were found among student nurses (Kao et al., 2013, Klunklin et al., 2010) and Collins (2004) study on radiographers and engineering students (Litzinger et al., 2005). A study on undergraduate nursing students by Klunklin et al. (2010) who reported that high SDLR was related to personal characteristics such as individual effort, autonomy, accountability, learning ability and analysing one's own learning needs. Future studies should investigate the design and delivery of tailormade SDL resources based on personality traits. The findings are essential for the understanding and self-defining eligibility when undertaking SDL activities, especially in the context of current nursing practice as professional regulators expect qualified nurses to engage in SDL (Department of Nursing Services, Brunei 2010).

This review also revealed that the correlation between SDLR and age and gender was not statistically significant for nurses and midwives' SDLR (Malekian et al., 2014). Studies among student nurses however provided divided views. For example, studies by Chen et al. (2006) and Roberson and Merriam (2005) among nursing students reported that SDLR was not related to age and gender. Similarly, a descriptive correlational study on 81 medical and dentistry students reported that there was no demographic influence on SDLR (Nadi and Sadjadian, 
2011). Contrastingly, a study by Kao et al. (2013) among nursing students reported that the key domain score of SDLR was significantly different between students aged 21-22 years and students aged 18-19 years. Similar to this, a study by Nikitenko (2009) on 240 graduate and undergraduate social science students, found that age significantly affected SDL readiness. Slater et al. (2017) who conducted a study among allied health sciences students comprising 69 occupational therapy students, 61 physiotherapy students, 148 sports science students and 35 podiatry students also reported the same findings that SDLR increased with age. Such discrepancies may lead to the claim that qualified and mature nurses have dissimilar SDLR learning attributes to student nurses. However, the limited number of papers in this review indicates a need for further studies to investigate personal characteristics associated with SDLR

Secondly, reviewed studies suggest that workplace environment had a significant impact on SDL (Nokdee, 2007; Ghiyasvandian et al., 2016; Malekian et al., 2014). This is similar to studies among student nurses (Shirazi et al., 2013; (Alotaibi, 2016) that reported the learning environment was a key factor for emergency nursing and medical students in determining their level of SDLR. Interestingly, among other professionals a study of industrial workers by Phairachakul (2011) reported that there was no significant relationship between work experience and SDLR. Furthermore, this review found self-engagement learning activities at the workplace such as peer learning and reflection at work to be modes of SDL (Takase et al., 2015). Such SDL activities support and enhance nursing competence in clinical practice (Caldwell \& Grobbel, 2013). This is similar to a study by Yang and Jiang (2014) among nursing students, which revealed that SDLR had a significant positive and strong relationship with learning nursing competencies. Future studies exploring influential factors that affect SDLR in the work place is recommended to strengthen the workplace as a strong mediating environment for SDL among nurses and midwives.

Thirdly, this review suggests nurses have a positive interest in online learning as a mode of SDL, which increased SDLR and improved their knowledge acquisition (Gagnon et al., 2015). Furthermore, systematic reviews among nursing students reported that web-based nursing education proved to have a positive impact on knowledge and skill acquisition and also student 
satisfaction (Mc Cutcheon et al., 2015; Du et al., 2013). Furthermore, this review found that selective topic areas might influence online SDLR among nurses. Future research with larger samples and multicentre trials should endorse such findings with respect to the relationship between subject area and SDLR.

This integrated review also explored the unique 'process components of SDL' among nurses and midwives. Firstly, it was found that the key components of SDL were engaging with intellectual and experiential activities for knowledge acquisition and skill development (Nokdee, 2007). This is similar to a study by Shirazi et al. (2017) on post graduate nursing students which explored active seeking, problem analysis and interaction with peers as the identified intellectual and experiential activities and concluded that knowledge acquisition is developed by cognition mapping in absorbing information and selecting appropriate learning strategies. Such components of SDLR are aligned with the Knowles (1975) theory of SDL, which endorses that adult learners have the ability to self-assess their own learning needs and engage appropriate action to achieve their learning goals. Furthermore, a study by Sawatsky et al. (2017) among 46 internal medical residencies detailed the conceptual SDL model for medical residencies. This model emphasises the process of self-directed learning is affected by two main factors namely, personal characteristics (internal locus of control) and contextual factors (external locus of control). Yet, little is known about how this model might apply to nurses. Hence, future research should explore this by developing and testing models of SDLR among nurses and midwives.

\section{Implications for nursing and midwifery practice and education}

This synthesised review of SDLR among nurses and midwives provides evidence that predictors of SDLR are dependent on individual personal characteristics and a supportive work place rather than demographic characteristics. Nurse educators and nurse managers in the health care system should be responsible for developing SDL mediating environments and related policies. Moreover, the review also identified online learning as a preferred mode of SDL. Nurse Educators should develop and support nurses and midwives through the use of different SDL approaches such as online learning, peer learning and reflection methods. The unique components of SDLR should be considered integral to developing strategies for promoting SDL. 
Continuing Nursing and Midwifery Education activities need to be tailored and enhanced so as to prepare nurses and midwives for SDL as lifelong learning to meet the needs of the ever-changing complex health care system.

\section{Conclusion}

The review concludes that qualified nurses and midwives have unique SDL predictors and a process. In particular, we recommend that a personalised SDL programme should be prescribed based on personality traits in order to achieve better outcomes of SDL for nurses and midwives. Furthermore, this review also concludes that engaging in SDL among nurses and midwives enhances not only knowledge acquisition, but also helps nurses to enhance their clinical skills, professional and teaching competencies. Future research should address the facilitating factors for SDLR, barriers to SDLR and strategies to improve SDLR among nurses and just as importantly among midwives as it is clear from the review that there is little evidence concerning the latter.

\section{References}

Alotaibi, K. N. (2016). The learning environment as a mediating variable between SDLR and academic performance of a sample of saudi nursing and medical emergency students. Nurse Education Today. 2016 Jan; 36:249-54. doi: 10.1016/j.nedt.2015.11.003. Epub 2015 Nov 10.https://www.ncbi.nlm.nih.gov/pubmed/26586258

Klunklin Areewan, Nongkran Viseskul, Acharaporn Sripusanapan, Sue Turale ded (2010). Readiness for SDL among nursing students in Thailand Authors http://onlinelibrary.wiley.com/doi/10.1111/j.1442-2018.2010.00515.x/full

Bahn. (2007). Orientation of nurses towards formal and informal learning: motives and perceptions. Nurse Education Today. 2007 Oct; 27(7):723-30. Epub 2006 Nov 28. https://www.ncbi.nlm.nih.gov/pubmed/17126454 
Predictors for Nurses and Midwives' Readiness towards Self-Directed Learning

Hosseini, Bidokht, M., \& Assareh, A. (2011). Life-long learners through problem-based and self directed learning. Procedia Computer Science, 3, 1446-1453.

Broome, M. E. (1993) Integrative literature reviews for the development of concepts. In Concept Development in Nursing, 2nd edition, (Rodgers, B. L. \& Knafl, K. A., eds), W. B. Saunders Co., Philadelphia, PA, pp. 231-250.

Brown, S. A., Upchurch, S. L., \& Acton, G. J. (2003). A framework for developing a coding scheme for meta-analysis. Western Journal of Nursing Research 25, 205-222.

Caldwell, L., \& Grobbel, C. (2013). The Importance of Reflective Practice in Nursing. International Journal of Caring Sciences, 6(3), 319-326. https://doi.org/International Journal of Caring Sciences September - December 2013 Vol 6 Issue 3

Chambers, D., Thiekötter, A., \& Chambers, L. (2013). Preparing student nurses for contemporary practice: The case for discovery learning. Journal of Nursing Education and Practice, 3(9), 106-113. https://doi.org/10.5430/jnep.v3n9p106

Chen, Y.-F., Wang, C.-M. \& Lin, H.-J. 2006. Explore the relationships among demography, personality traits and self-directed learning. The Journal, 141.

Chen, Y., Hsu, L., \& Hsieh, S. 2012, 'Clinical nurse preceptor teaching competencies:

Relationship to locus of control and SDL', The Journal of Nursing Research 20(2), 142-150. PMID: 22592109, http://dx.doi.org/10.1097/JNR.0b013e318254ea72

Cleary, M., \& Freeman, A. (2006). Enhancing nurse carer partnerships: A self-directed learning approach. Nurse Education in Practice, 6(4), 224-231. https://doi.org/10.1016/j.nepr.2006.01.005

Collins, J. (2004). Education techniques for lifelong learning: principles of adult learning. Radiographics : A Review Publication of the Radiological Society of North America, Inc, 24(5), 1483-1489. https://doi.org/10.1148/rg.245045020

Dalhem, W. A., \& Saleh, N. (2014). The impact of eLearning on nurses' professional knowledge and practice in HMC. Canadian Journal of Nursing Informatics, 9(3-4), 1-13. Retrieved from http://search.proquest.com/docview/1698428282?accountid=14477\%5Cnhttps://nevada.ual.es /biblioteca/gtb/sod/poa login.php?centro=\$UALMG\&sid=\$UALMG\&title=Canadian + Journa $\underline{1+\text { of }+ \text { Nursing }+ \text { Informatics\&atitle }=\text { The }+ \text { impact }+ \text { of }+ \text { eLearning }+ \text { on }+ \text { nurses' }+ \text { professional }+ \text { kno }}$ $\underline{\text { wledge }}+$ 
Predictors for Nurses and Midwives' Readiness towards Self-Directed Learning

Department of Nursing Services. (2010). Standards of Practice for registered nurses and midwives. Department of Nursing Services, Ministry of Health, Brunei Darussalam,8-9.

Demir Kaymak, Z., \& Horzum, M. B. (2013). Relationship between online learning readiness and structure and interaction of online learning students. Kuram ve Uygulamada Egitim Bilimleri, 13(3), 1792-1797. https://doi.org/10.12738/estp.2013.3.1580

Donald N. Roberson, J., \& Merriam, S. B. (2005). The Self-Directed Learning Process of Older, Rural Adults. Adult Education Quarterly, 55(4), 269-287.

https://doi.org/10.1177/0741713605277372

Du, S., Liu, Z., Liu, S., Yin, H., Xu, G., Zhang, H., \& Wang, A. (2013). Web-based distance learning for nurse education: A systematic review. International Nursing Review, 60(2), 167177. https://doi.org/10.1111/inr.12015

El, N., Sofar, S. M., Ali, J., \& Al-battawi, I. (2017). Self-directed learning readiness among Nursing Students at KingAbdulazizUniversity, Saudi Arabia ., 6(6), 14-24. https://doi.org/10.9790/1959-0606031424

Farokhi Far, M., Foroud Nia, F. \& Razavi, S. 2002. A survey of comparison of nurses' attitudes towards selfdirected and other-directed continuing education programs in nursing at Kerman University of Medical Sciences. Armaghane Danesh Journal of Yasuj University of Medical Sciences, 26, 45-9.http://www.sid.ir/En/Journal/SearchPaper.aspx?writer=44969

Gagnon, J., Gagnon, M. P., Buteau, R. A., Azizah, G. M., Jetté, S., Lampron, A., ... Reviriego, E. (2015). Adaptation and evaluation of online self-learning modules to teach critical appraisal and evidence-based practice in nursing: An international collaboration. CIN Computers Informatics Nursing, 33(7), 285-294. https://doi.org/10.1097/CIN.0000000000000156

Ghiyasvandian, S., Malekian, M., \& Cheraghi, M. A. (2015). Iranian Clinical Nurses' Activities for Self-Directed Learning: A Qualitative Study. Global Journal of Health Science, 8(5), 48. https://doi.org/10.5539/gjhs.v8n5p48

Ito, M., Hattori, K., \& Kakeda, T. (2017). Examining the Criterion-related Validity of the SelfDirected Learning Ability Scale for Clinical Nurses, 22(2), 103-110.

Knowles, M. 1975. Self-directed learning: A guide for teachers and learners. Chicago, IL: Follett. 
Predictors for Nurses and Midwives' Readiness towards Self-Directed Learning

Knowles, M. S., Holton III, E. F. \& Swanson, R. A. 2014. The adult learner: The definitive classic in adult education and human resource development, Routledge.

Lahti, M., Hätönen, H., \& Välimäki, M. (2014). Impact of e-learning on nurses' and student nurses knowledge, skills, and satisfaction: A systematic review and meta-analysis. International Journal of Nursing Studies. https://doi.org/10.1016/j.ijnurstu.2012.12.017

Litzinger, T. A., Wise, J. C. \& Lee, S. H. 2005. Self-directed Learning Readiness Among Engineering Undergraduate Students. Journal of Engineering Education, 94, 215-221.

Malekian, M., Ghiyasvandian, S., Cheraghi, M. A., \& Hassanzadeh, A. (2015). Iranian Clinical Nurses’ Readiness for Self-Directed Learning. Global Journal of Health Science, 8(1), 157. https://doi.org/10.5539/gihs.v8n1p157

Mayer, C., Andrusyszyn, M.-A., \& Iwasiw, C. (2005). Codman Award Paper: self-efficacy of staff nurses for health promotion counselling of patients at risk for stroke. Axone (Dartmouth, N.S.), 26(4), 14-21. Retrieved from http://www.ncbi.nlm.nih.gov/pubmed/16028726

McCutcheon, K., Lohan, M., Traynor, M., \& Martin, D. (2015). A systematic review evaluating the impact of online or blended learning vs. face-to-face learning of clinical skills in undergraduate nurse education. Journal of Advanced Nursing, 71(2), 255-270. https://doi.org/10.1111/jan.12509

Middleton, L., \& Llewellyn, D. (2016). How to record and evidence practice hours for revalidation. Nursing Standard (Royal College of Nursing (Great Britain) : 1987), 30(43), 42-46. https://doi.org/10.7748/ns.2016.e10513

Moher, D., Liberati, A., Tetzlaff, J., \& Altman, D. G. (2009). Preferred reporting items for systematic reviews and meta-analyses: the PRISMA statement. BMJ, 339(jul21 1), b2535b2535. https://doi.org/10.1136/bmj.b2535

Montin, L., \& Koivisto, J.-M. (2014). Effectiveness of self-directed learning methods compared with other learning methods in nursing education related to nursing students' or registered nurses' learning outcomes: A systematic review protocol. JBI Database of Systematic Reviews and Implementation Reports, 12(2), 1-8. https://doi.org/10.11124/jbisrir-2014-532

Murad, M. H., \& Varkey, P. (2008). Self-directed Learning in Health Professions Education. Annals, Academy of Medicine, Singapore, 37, 580-590. 
Predictors for Nurses and Midwives' Readiness towards Self-Directed Learning

Nadi, M. A. \& Sadjadian, I. 2011. Validation of a Self-directed Learning Readiness Scale for Medical and Dentistry Students. Iranian Journal of Medical Education, 11. 8(2):173-181 1http://sdmej.ir/article-1-101-en.pdf

Nikitenko, G. 2009. Correlational Analysis of Adult Students' Self-Directed Learning Readiness, Affective Learning Outcomes, Prior Electronic Learning Experience, and Age in Hybrid and Online Course-Delivery Formats. ProQuest LLC.

Nokdee, S. (2007). Self-Directed Learning among Thai Nurses in Clinical Practice, 1-206. doi $=10.1 .1 .631 .2144 \&$ rep $=$ rep1\&type $=$ pdf

O'Shea, E. (2003). Self-directed learning in nurse education: A review of the literature. Journal of Advanced Nursing. https://doi.org/10.1046/j.1365-2648.2003.02673.x

Öztürk, D., Çalişkan, N., Baykara, Z. G., Karadağ, A., \& Karabulut, H. (2015). Determining the effect of periodic training on the basic psychomotor skills of nursing students. Nurse Education Today, 35(2), 402-407. https://doi.org/10.1016/j.nedt.2014.10.023

Peters, M., Godfrey, C., Mcinerney, P., Soares, C., Khalil, H. \& Parker, D. 2015. The joanna briggs institute reviewers' manual 2015: methodology for JBI scoping reviews.

Phairachkul, T. (2011). Self-Directed Learning Readiness of Industrial Workers, (June), 1-5. Purkis, N., \& Gabb, C. A. (2013). Online learning professional development. Nursing Times, 109(51), 16-18. Retrieved from http://ovidsp.ovid.com/ovidweb.cgi?T=JS\&PAGE=reference \&D=medl\&NEWS=N\&AN=245 $\underline{92659}$

Ramasamy Venkatasalu, M., Sirala Jagadeesh, N., Elavally, S., Pappas, Y., Mhlanga, F. \& Pallipalayam Varatharajan, R. 2017. Public, patient and carers' views on palliative and end-of-life care in India. International nursing review.

Roberson, D. N., \& Merriam, S. B. (2005). The self-directed learning process of older, rural adults. Adult Education Quarterly, 55(4), 269-287. https://doi.org/10.1177/0741713605277372

Salmond, S. W., \& Echevarria, M. (2017). Healthcare Transformation and Changing Roles for Nursing. Orthopaedic Nursing, 36(1), 12-25. https://doi.org/10.1097/NOR.0000000000000308 
Predictors for Nurses and Midwives' Readiness towards Self-Directed Learning

Sawatsky, A. P., Ratelle, J. T., Bonnes, S. L., Egginton, J. S., \& Beckman, T. J. (2017). A model of self-directed learning in internal medicine residency: a qualitative study using grounded theory. BMC Medical Education, 17(1), 31. https://doi.org/10.1186/s12909-017-0869-4

Şenyuva, E., \& Kaya, H. (2014). Effect Self Directed Learning Readiness of Nursing Students of the Web Based Learning. Procedia - Social and Behavioral Sciences, 152, 386-392. https://doi.org/10.1016/j.sbspro.2014.09.217

Sharples, K., \& Moseley, L. G. (2010). Learning to learn in practice: An evaluation of a 35-day practice orientation programme. Nurse Education in Practice, 10(2), 57-63. https://doi.org/10.1016/j.nepr.2009.03.009

Shirazi, F., Sharif, F., Molazem, Z., \& Alborzi, M. (2017). Dynamics of self-directed learning in M.Sc. nursing students: A qualitative research. Journal of Advances in Medical Education \& Professionalism, 5(1), 33-41. Retrieved from http://www.ncbi.nlm.nih.gov/pubmed/28124019

Slater, C. E., Cusick, A., \& Louie, J. C. Y. (2017). Explaining variance in self-directed learning readiness of first year students in health professional programs. BMC Medical Education, 17(1), 207. https://doi.org/10.1186/s12909-017-1043-8

Soliman, M., \& Al-Shaikh, G. (2015). Readiness for self-directed learning among First Year Saudi Medical students: A descriptive study. Pakistan Journal of Medical Sciences, 31(4), 799-802. https://doi.org/10.12669/pjms.314.7057

Takase, M., Yamamoto, M., Sato, Y., Niitani, M., \& Uemura, C. (2015). The relationship between workplace learning and midwives' and nurses' self-reported competence: A crosssectional survey. International Journal of Nursing Studies, 52(12), 1804-1815. https://doi.org/10.1016/j.ijnurstu.2015.06.016

Thorne, S. E. (2006). Nursing education: key issues for the 21 st century. Nurse Education Today, 26(8), 614-621. https://doi.org/S0260-6917(06)00110-9 [pii]

Torraco, R. J. (2005). Writing Integrative Literature Reviews: Guidelines and Examples. Human Resource Development Review, 4(3), 356-367. https://doi.org/10.1177/1534484305278283

Van Rensburg, G. H., \& Botma, Y. (2015). Bridging the gap between self-directed learning of nurse educators and effective student support. Curationis, 38(2), 1503. https://doi.org/10.4102/curationis.v38i2.1503 
Predictors for Nurses and Midwives' Readiness towards Self-Directed Learning

Whittemore, R. \& Knafl, K. 2005. The integrative review: updated methodology. Journal of advanced nursing, 52, 546-553.

Wiley, K. 1983. Effects of a self-directed learning project and preference for structure on selfdirected learning readiness. Nursing Research, 32, 181-185.

Yang, G. F., \& Jiang, X. Y. (2014). Self-directed learning readiness and nursing competency among undergraduate nursing students in Fujian province of China. International Journal of Nursing Sciences, 1(3), 255-259. https://doi.org/10.1016/j.ijnss.2014.05.021 


\begin{tabular}{|l|l|}
\hline Inclusion criteria & Exclusion criteria \\
\hline Studies published between 2000-2017 & Studies published before the year 2000 \\
\hline $\begin{array}{l}\text { Primary research papers including both } \\
\text { qualitative studies and quantitative studies }\end{array}$ & $\begin{array}{l}\text { Grey literature, Policy documents, Expert } \\
\text { opinions }\end{array}$ \\
\hline $\begin{array}{l}\text { Studies included nurses and midwives as } \\
\text { participants }\end{array}$ & $\begin{array}{l}\text { Studies that included student nurses and/or } \\
\text { student midwives }\end{array}$ \\
\hline Studies reported in English & Studies that were not reported in English \\
\hline Studies focused on SDLR & \\
\hline
\end{tabular}

Table 1: Inclusion and exclusion criteria 
Table 2: Included studies on nurses and midwives' readiness towards SDL

\begin{tabular}{|c|c|c|c|c|c|}
\hline No. & Author \& Year & Aims \& Objectives & $\begin{array}{c}\text { Sample, Sampling } \\
\text { technique \& Settings }\end{array}$ & Methodology & Key Findings \\
\hline 1. & $\begin{array}{l}\text { Malekian et al. } \\
\text { (2014) }\end{array}$ & $\begin{array}{l}\text { To assess the readiness } \\
\text { towards SDL among } \\
\text { clinical nurses in relation } \\
\text { to their personal } \\
\text { characteristics. }\end{array}$ & $\begin{array}{l}\text { Sample: } 314 \text { nurses } \\
\text { Sampling technique: } \\
\text { Stratified sampling } \\
\text { Setting: Affiliated Hospitals } \\
\text { (Iran) }\end{array}$ & $\begin{array}{l}\text { Design: Cross- sectional } \\
\text { Survey } \\
\text { Instrument: SDLRS } \\
\text { (SDLR Scale) }\end{array}$ & $\begin{array}{l}\text { - Age, gender and marital status of the } \\
\text { nurses does not influence SDLR. } \\
\text { - Work experience and past academic } \\
\text { achievement of the nurses have a } \\
\text { significant correlation with the self- } \\
\text { management domain of SDLR. }\end{array}$ \\
\hline 2. & $\begin{array}{l}\text { Gagnon, J. et al. } \\
\text { (2015) }\end{array}$ & $\begin{array}{l}\text { To assess the effect of } \\
\text { online self-directed } \\
\text { learning modules in the } \\
\text { implementation of } \\
\text { research among nurses in } \\
\text { clinical practice. }\end{array}$ & $\begin{array}{l}\text { Sample: } 83 \text { nurses } \\
\text { Sampling technique: } \\
\text { Convenience sampling } \\
\text { Setting: University hospital } \\
\text { in Quebec (Canada) and the } \\
\text { Public Health Service in the } \\
\text { Basque (Spain) }\end{array}$ & $\begin{array}{l}\text { Design: Quantitative study } \\
\text { (A prospective pre post study) } \\
\text { Instrument: SDLRS }\end{array}$ & $\begin{array}{l}\text { - Nurses had increased level of SDLR } \\
\text { domains with online learning. } \\
\text { - Online learning was reported as an } \\
\text { integral part of continuing education. }\end{array}$ \\
\hline 3. & $\begin{array}{l}\text { Ito et al. } \\
\text { (2016) }\end{array}$ & $\begin{array}{l}\text { To analyse the criterion- } \\
\text { related validity of the SDL } \\
\text { Ability Scale and examine } \\
\text { its concurrent validity with } \\
\text { the SDLRS. }\end{array}$ & $\begin{array}{l}\text { Sample: } 1655 \text { nurses } \\
\text { Setting: } 3 \text { General hospitals } \\
\text { and } 3 \text { specific hospitals } \\
\text { (Japan) }\end{array}$ & $\begin{array}{l}\text { Design: Quantitative study } \\
\text { (Self administered } \\
\text { questionnaire) } \\
\text { Instruments: SDLRS } \\
\text { SDLAS (SDL Ability Scale) }\end{array}$ & $\begin{array}{l}\text { - SDLR was associated with nurses } \\
\text { intention to grow and develop } \\
\text { accountability in self learning }\end{array}$ \\
\hline 4. & $\begin{array}{l}\text { Takase et al. } \\
\text { (2015) }\end{array}$ & $\begin{array}{l}\text { To evaluate the learning } \\
\text { methods adopted by nurses } \\
\text { with different working }\end{array}$ & $\begin{array}{l}\text { Sample: } 954 \text { nurses } \\
\text { /midwives }\end{array}$ & $\begin{array}{l}\text { Design: Quantitative Study } \\
\text { (Cross-sectional survey) }\end{array}$ & $\begin{array}{l}\text { SDL of nurses in the workplace was } \\
\text { fostered by reflection of their work } \\
\text { experience. }\end{array}$ \\
\hline
\end{tabular}




\begin{tabular}{|c|c|c|c|c|c|}
\hline & & $\begin{array}{l}\text { experience and its } \\
\text { association with nurses' } \\
\text { competence. }\end{array}$ & $\begin{array}{l}\text { Sampling technique: } \\
\text { Convenience sampling } \\
\text { Setting: University hospitals } \\
\text { (Japan) }\end{array}$ & $\begin{array}{l}\text { Instruments: Learning } \\
\text { Experience Scale } \\
\text { Self-Reported competence } \\
\text { scale }\end{array}$ & $\begin{array}{l}\text { Nurses and midwives self-reported } \\
\text { competence is increased in association } \\
\text { with the learning from feedback and } \\
\text { experience. }\end{array}$ \\
\hline 5. & $\begin{array}{c}\text { Mayer, } \\
\text { Andrusyszyn } \\
\text { and Iwasiw } \\
\text { (2005) }\end{array}$ & $\begin{array}{l}\text { To evaluate the effect of } \\
\text { nurses' confidence who } \\
\text { counsel patients at risk of } \\
\text { stroke. }\end{array}$ & $\begin{array}{l}\text { Sample: } 76 \text { Neuroscience } \\
\text { nurses } \\
\text { Sampling technique: } \\
\text { Convenience sampling } \\
\text { Setting: Quaternary hospital }\end{array}$ & $\begin{array}{l}\text { Design: Quantitative study (A } \\
\text { prospective pre post study). } \\
\text { Instrument: The Health } \\
\text { Promotion Counseling Self- } \\
\text { Efficacy Scale }\end{array}$ & $\begin{array}{l}\text { Demographic characteristics did not } \\
\text { influence the self-efficacy towards SDL. } \\
\text { - Nurses expressed interest in SDL and } \\
\text { their self-efficacy is increased after } \\
\text { completing the SDL module. }\end{array}$ \\
\hline 6. & $\begin{array}{l}\text { Chen et al. } \\
\text { (2012) }\end{array}$ & $\begin{array}{l}\text { To examine clinical nurse } \\
\text { preceptors teaching } \\
\text { competence in relation to } \\
\text { SDL. }\end{array}$ & $\begin{array}{l}\text { Sample: } 243 \text { clinical nurse } \\
\text { preceptors } \\
\text { Sampling technique: } \\
\text { Convenience sampling } \\
\text { Setting: Medical center in } \\
\text { northern Taiwan. }\end{array}$ & $\begin{array}{l}\text { Design: Quantitative study } \\
\text { (Descriptive and co-relational } \\
\text { study) } \\
\text { Instrument: SDLRS }\end{array}$ & $\begin{array}{l}\text { - Significant correlation between SDL } \\
\text { and teaching competence among } \\
\text { nurses. } \\
\text { - Teaching competence rose as SDL } \\
\text { increased. }\end{array}$ \\
\hline
\end{tabular}


Predictors for nurses and midwives' readiness towards SDL

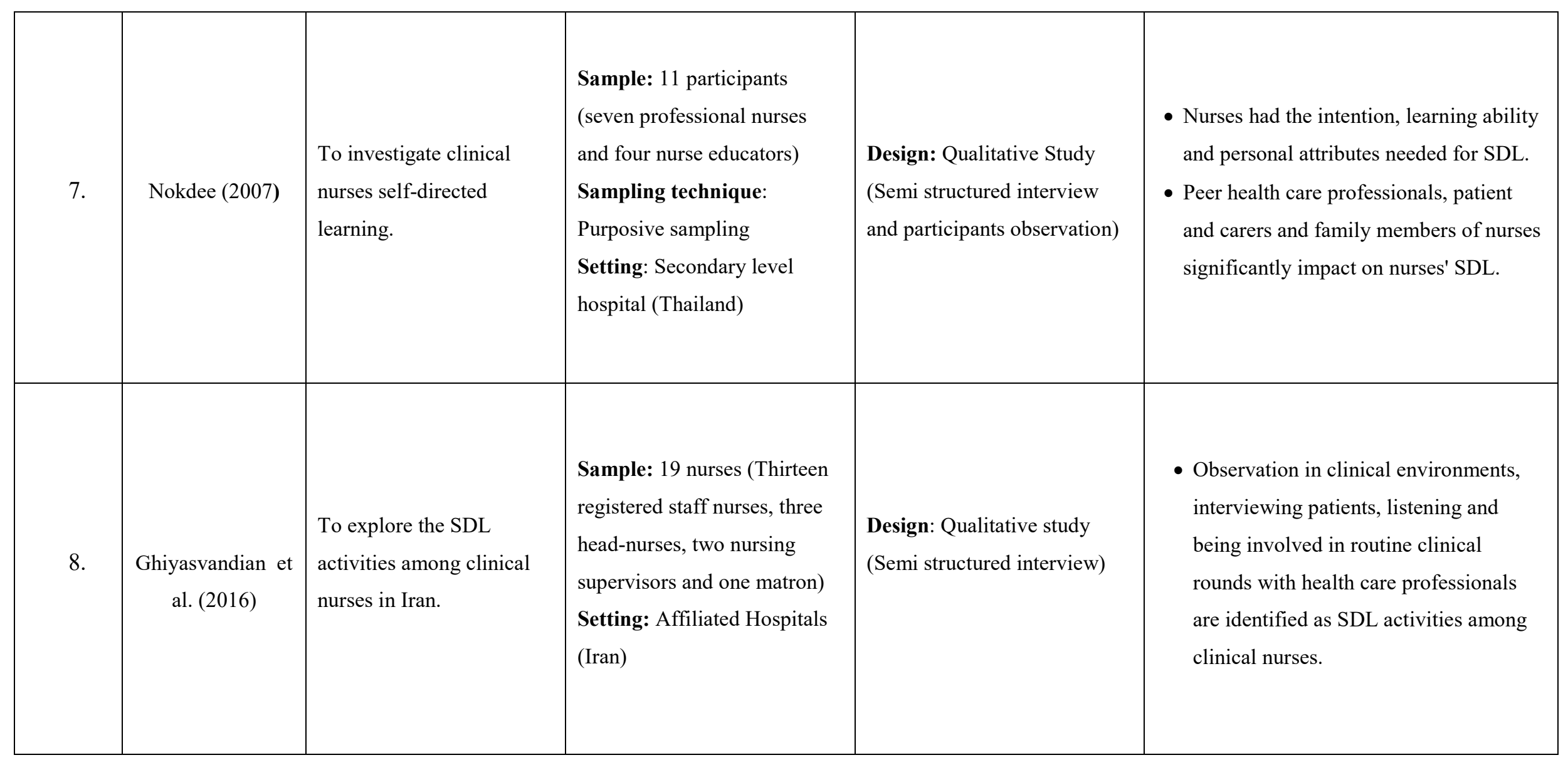




\section{Nurses and midwives' readiness towards self-directed learning}

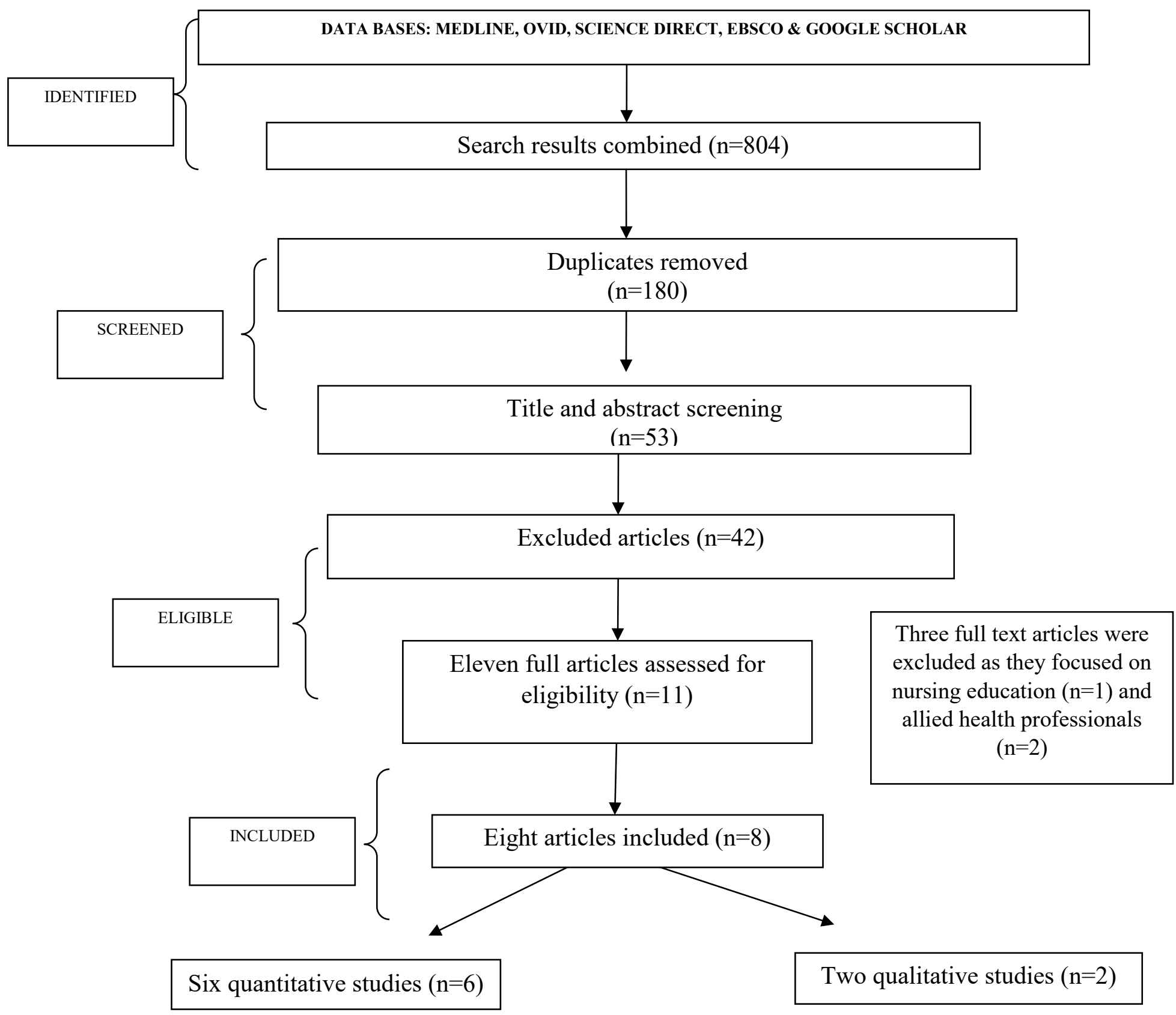

Figure: 1 PRISMA Chart 
Predictors for nurses and midwives' readiness towards SDL 